In the growing-finishing pig trial, feeds including raw rapeseed were eaten more slowly than the control feed. Feed conversion ratio of diets containing 5 and $10 \%$ raw rapeseed was 5.3 and $9.1 \%$ higher than that of the control diet. The $10 \%$ extruded rapeseed diet led to the same results as the control diet. Fat content of carcasses was similar whatever the diet. By contrast, liver weight and consequently dressing percentage were affected by the presence of raw rapeseed in the diet.

\title{
Feeding value of barley-based fat enriched diets for weaned piglets
}

\author{
J. FEKETE ${ }^{(1)}$, F. GATEL ${ }^{(1)}$, J. CASTAING ${ }^{(2)}$, M. SEROUX ${ }^{(1)}$ \\ (1) I.T.C.F., 8, avenue du Président-Wilson, 75116 Paris. \\ (2) A.G.P.M., 122, boulevard Tourasse, 64000 Pau.
}

Three trials involving 1539 piglets weaned between 9 and $24 \mathrm{~kg}$ were conducted to study the effect of fat incorporation into barley-based diets. Different fat contents were tested : 3.5 and $7 \%$ animal fat (trial I), 10 and $20 \%$ extruded soybean seeds (trial II) and 2.5 and $5 \%$ soybean oil (trial III).

Feed conversion ratio decreased significantly with the increase in dietary fat content (or digestible energy content $)=-5 \%$ and $-6 \%$ with 3.5 and $7 \%$ fat, -2 and $-5 \%$ with 10 and $20 \%$ soybean seeds, -5 and $-7 \%$ with 2.5 and $5 \%$ soybean oil. This was obtained either by a decreased feed intake (with animal fat or $5 \%$ oil) or by a faster growth rate (with soybean seeds or $2.5 \%$ oil).

\section{Utilization of grain maize silages with or without cobs by the weaned piglet}

\author{
J. CASTAING ${ }^{(1)}$, R. COUDURE ${ }^{(1)}$, J. FEKETE ${ }^{(2)}$ \\ (1) A.G.P.M., 122, boulevard Tourasse, 64000 Pau. \\ (2) I.T.C.F., 8, avenue du Président-Wilson, 75116 Paris.
}

Four trials involving 1736 piglets between 9 and $25 \mathrm{~kg}$ live weight were made to study different maize silages supplemented with soybean meal and minerals and vitamins, Animals were fed ad libitum. In the first trial, moist grain maize silage (MGH) and maize grain silage with about $90 \%$ cobs (MGR 90) were compared to a control dry grain maize silage (MGS). In the second trial, the same diets were used as well as a fourth diet composed of maize silage $+100 \%$ cobs (MGR 100). In the third trial, finely ground MGR 90 (particle size : $0.63 \mathrm{~mm}$ ) and more coarsely ground MGR 90 (particle size : $0.83 \mathrm{~mm}$ ) were compared to dry grain maize. In the fourth trial, two varieties of maize were compared in MGH or MGR 90 silages. In each trial, silages came from the same field.

On an average and on the basis of the same water content of maize, feed intake was $2 \%$ higher with MGH than with MGS. Feed conversion ratios were similar with these two diets. MGR based diets led to a $2 \%$ higher feed intake than $\mathrm{MGH}$ based diets. Feed conversion ratio of MGR diets was $3 \%$ higher than that of MGH diets. Particle size of MGR 90 silages did not affect either feed intake or growth of the animals. There was no interaction between the type of silage (MGH or MGR 90) and the maize variety; thus performance of piglets were similar with both varieties. 